\title{
Revisiting the impacts of tourism from the perspective of social space production: An ethnological study of the Muslim community in Sanya, Hainan Province, China
}

\author{
Jiuxia Sun $^{1}$ Shiqin Zhang ${ }^{2 *}$ Mingjie $\mathrm{Ji}^{3}$ \\ ${ }^{1}$ School of Tourism Management, Sun Yat-sen University, Guangzhou, China \\ ${ }^{2}$ School of Hotel and Tourism Management, The Hong Kong Polytechnic University, Hong \\ Kong
}

${ }^{3}$ Oxford School of Hospitality Management, Business School, Oxford Brookes University, United Kingdom

* Corresponding author. E-mail: shiqin.zhang@connect.polyu.hk (ZHANG, Shiqin), zhangshiqin37@163.com (ZHANG, Shiqin); Tel.: +852 55795337; Address: 17 Science Museum Road, TST East, Kowloon, Hong Kong.

Jiuxia Sun is Professor of School of Tourism Management at the Sun Yat-sen University (135 Xingangxi Road, Guangzhou, Guangdong, China. Email < sunjx@mail.sysu.edu.cn>). She has authored books on ethnic group, culture, tourism anthropology, tourist behavior and her research concentrates on community tourism and community participation, tourism anthropology and sociology, tourism and ethnic relations, tourism and social space.

Shiqin Zhang is a PhD candidate of School of Hotel and Tourism Management at the Hong Kong Polytechnic University (17 Science Museum Road, TST East, Kowloon, Hong Kong. Email <shiqin.zhang@connect.polyu.hk>). Her research interests are tourism management, tourism and social space, greenway tourism, sustainability.

Dr. Mingjie Ji is a senior lecture in the Business School at Oxford Brookes University (Headington Campus, Oxford, UK. Email< mji@brookes.ac.uk $>$ ). Her research interests are tourist behaviour modelling and embodied experiences. 


\section{Revisiting the impacts of tourism from the perspective of social space production: An ethnological study of the Muslim community in}

\section{Sanya, Hainan Province, China}

'Tourism' has been regarded as an essential driving force behind destination changes. On reflection, it is essentially not tourism, but the mechanisms underlying destination development process that lead to the changes. However, very few studies have explored these mechanisms with the majority of work simply comparing the pre- and post-tourism stages to conclude the effects of tourism on destinations. The current study builds on Lefebvre's social space production epistemology to establish a conceptual framework to decipher the mechanisms. It was illustrated using the context of the Muslim community in Sanya, Hainan Province, China. Results demonstrate that the dynamic relationship between capital, culture and power initiated the production of the community space. Capital facilitated the production of 'spatial practices', which interacted with the 'representations of space' dominated by the (administrative) power and the 'representational space' produced by the Muslim culture. Theoretical implications of the framework for social changes are also discussed.

Keywords: tourism impacts; destination change; space production; capital; power; culture 


\section{Introduction}

The global tourism industry has developed rapidly and has led to many social changes over the last 50 years (Nicholls, 2004; Pratt, 2011). The impacts of tourism on host communities, which present insights into the social changes that occurred therein, have drawn extensive academic attention (Getz, 1992; Leiper, 1990; Nunkoo, Smith, \& Ramkissoon, 2013; Woo, Uysal, \& Sirgy, 2018). Deery, Jago and Fredline (2012, p. 65) reviewed the rapid growth of related research and claimed that the tourism impact research has been 'incremental at best, or potentially circular'. The emphasis on quantitative approaches and the absence of theoretical depth were found to be responsible for the problem (Nunkoo et al., 2013). The present study argues that the outcome-based epistemology and the descriptive approach are another two essential problems that hinder the advancement of this body of knowledge.

The outcome-based epistemology studies tourism impact by comparing a destination's pre- and post-tourism development status. Any changes that have taken place between the status are attributed to tourism development. This approach is over simplistic and does not pay attention to the process, during which the destination undergoes varying changes. Regarding the varying outcomes, the relationship between tourism development and host communities came to be ambivalent. Sometimes tourism was regarded as a facilitator of economic development, intercultural communication and heritage protection (Hampton, 2005; Ishii, 2012). While in other situations, tourism was found to produce cultural commercialisation and assimilation (Cheer, Reeves, \& Laing, 2013; Greenwood, 1989), environmental degradation and social conflicts caused by unfair wealth distribution (Inchausti-Sintes, 2015; Pitchford, 1995). Consequently, ethnic communities struggle to develop a tourism economy (e.g. Yang, Ryan, \& Zhang, 2016; Yang, Wall, \& Smith, 2008). A comprehensive exploration which theorises the destination change process must be conducted to accommodate these variations and posit the very role of developing tourism.

In existing literature, the descriptive approach which refers to examining multiple cases for the general rational in varying outcomes is common (Ruhanen, Moyle, \& Moyle, 2018). Abundant descriptions however are only helpful in either fragmenting the outcomes of destination changes or explaining individual scenarios (Mazanec, 2009; McKercher \& Prideaux, 2014). For instance, contextual explanations such as economic level, place identity and public media have been identified in different cases (Chen, Lin, \& Chiu, 2016; Wang \& Chen, 2015). No universal rational was generated. The descriptive approach limits the academic rigor in theorising destination development. A more effective approach, from a Marxist dialectics view, should be a holistic and coherent theoretical framework that is able to abstract the process of destination changes so that the underlying drivers and mechanisms can be developed, benefiting 
all destinations and enlightening tourism impact research (Bao, Chen, \& Ma, 2014; Deery et al., 2012).

The current study aims to examine the intrinsic mechanisms that underpin the process of destination changes by using Lefebvre's social space production theory (Elden, 2004; Harvey, 1989; Stanek, 2008). On the basis of a new and revolutionary ontology and epistemology that defines space as the social product in constant production and reproduction, this theory regards social change as the dynamic process of space production through a space triad (i.e. spatial practices, representations of space and representational space) (Lefebvre, 1991). Furthermore, it implies that capital, power and culture are the underpinning driving forces of the process. The theory was proposed at the industrial stage to build theoretical unity to comprehend complex social development and changes. The current study assumed it could also provide theoretical implications to the social changes in this tourism era.

The Muslim community in Sanya, Hainan was a typical context to study tourism impact as tourism has been a main economic pillar in the community. Moreover, the sociocultural evolution accompanying tourism over recent decades was witnessed as fast, dramatic and complex that intertwined various conflicts from politics, power and culture within and outside the community. By focusing on a rich context like the Muslim community in Sanya, profound insights and holistic understandings can be made regarding tourism impact.

The contribution of the present study is to advance the current understanding of tourism impacts that are essentially based on outcomes and a descriptive approach. It focuses on the process of destination change and proposes an alternative framework that involves capital, culture and power, as well as the dynamic relationships among them. The social space production theory that the framework is based on also provides an alternative lens to investigate various other major topics in tourism and hospitality studies.

\section{Literature review}

\section{Tourism impacts on host communities}

The development of the tourism impact research over the last three decades is limited to the linear historical view. This view assumes that 'time' is the basic logical premise of social development and tourism destinations therefore grow chronologically towards an outcome (Duara, 1996). This assumption is demonstrated by two main observations: the outcome-based causal deduction and the recursive description of destination changes. The former is illustrated using the platforms of Jafari (1989) and Wall and Ali's (1977) framework. The latter is supported by the case-based approach. 
The four platforms of tourism impact proposed by Jafari (1989) are helpful in consolidating the trends of relevant studies. The 'Advocacy Platform' stressed the economic benefits (Redman, 1983) of tourism to communities (Esman, 1984). By contrast, the 'Cautionary Platform' exposed the negative impacts of tourism on the environment, culture, lifestyle and identity of the communities (Smith, 1989; Teye, 1993). The 'Adaptive Platform' emphasised the potential of tourism to protect endangered heritages (Horn \& Simmons, 2002) and strengthen community identity through intercultural communication (Light, 2007; Medina, 2003). The 'Knowledge-based Platform' adopted the comparable cases by pursuing a comprehensive yet contextual understanding of tourism impact (Horn \& Simmons, 2002; Woo et al., 2018).

The above four platforms clearly marked the impacts of tourism and highlighted a contextual and descriptive trend for this field of study. However, such insights were based on comparisons of pre-and post-development stages of tourist destinations, regardless of whether they were 'advocacy platform' or 'cautionary platform'. Wall and Ali (1977) also replicated the weakness. They categorised tourism impacts into economic, environmental and cultural by a visual assessment of the community changes after tourism development. Those outcomes over the stages were bluntly attributed to 'tourism'. The associated drivers, forces and mechanisms in the process have not received much investigation. The present study proposes that such an outcome-based approach is uninformative to destination changes; a new perspective that focuses on the process of destination change is much needed.

In addition, existing research also suffers from the recursive description of impacts that are ineffective in theory deduction. To further understand the complexity of destination changes, tourism impact research has shifted from macro generalisation to a micro, case-based approach (Biddulph, 2015; Steel, 2012). For instance, Cárdenas-García, Sánchez-Rivero, and Pulido-Fernández (2015) suggested to examine economic impacts of tourism development on the basis of the destination-specific economic development level. The case-based approach is helpful to minimise impact biases (Biddulph, 2015). It has also informed a number of theories since the 1970s including assimilation theory (Nash, 1996), development stages theory (Akis, Peristianis, \& Warner, 1996; Doxey, 1975), social exchange theory (Ap, 1990) and cultural reproduction theory (Bourdieu \& Passeron, 1990). However, the theories still focus on linear descriptions, contextualise impact discussions and discourage formation of a universal theoretical interpretation (Benckendorff \& Zehrer, 2013).

The literature cited above highlights two research gaps concerning tourism impact studies: the outcome-based and recursive descriptive approaches. To address these research gaps, a distinctive approach that pays attention to the mechanisms during the course of tourism 
development is needed (Cornet, 2015; Deery et al., 2012; Nunkoo et al., 2013). The current study introduces 'the space production theory' as an alternative approach.

\section{Space production theory: A social space epistemology}

In the 1970s, Lefebvre (1991)1 proposed space production theory based on his reflection of social changes after World War II, which emphasised the social nature of space. This theory maintains that '(social) space is (social) product' (Lefebvre, 1991, p. 26) where space can be considered as dynamic and changeable in social evolution. Lefebvre's view towards space is in contrast with the then general linear historical view, which regarded time as rich, prolific, viable and dialectical but space as empty, stereotyped, non-dialectical and static (Foucault, 1986; Soja, 1996). By contrast the space production theory regarded space as productive with fruitful connotations (Lefebvre, 1991; McKercher, Wang, \& Park, 2015). Lefebvre's view (1991) has stimulated new epistemology and methodology for urbanology, sociology, geography and architecture (Boano, 2015).

The authors, based on Lefebvre's seminal work on space production, proposed a conceptual framework for the present study. As shown in Figure 1, the framework contains two layers, the inner circle and outer circle, with social relations as the core in the middle. Lefebvre assigned two important essences to social space in consideration of its productive and reproductive nature: the family-based biological relations of reproduction and the labour- or organisation-based socioeconomic relations of production. Consequently, social relations constitute the core of space production (Harvey, 1989; Lefebvre, 1991; Lin, 2015; Purcell, 2013).

The inner circle is based on Lefebvre's discussions on the spatial triad include spatial practices, representations of space and representational space (Elden, 2004). Spatial practices or perceived space refers to the "production and reproduction, and the particular locations and spatial sets characteristic of each social formation'(Lefebvre, 1991, p. 33) such as production practices, roads, networks and workplaces. Representations of space or conceived space refers to the knowledge and representational relations that enforce social order. It is the dominant space in any society controlled by scientists, planners and engineers (Lefebvre, 1991, pp. 3839), who impose social order through planning and regulations. Representational space or lived space embodies complex symbolisms that are 'linked to the clandestine or underground side of social life'(Lefebvre, 1991, p. 39), such as non-verbal symbols or codes to regulate behaviours. According to Lefebvre (1991), three dimensions interact to initiate space production and enact 
the production and reproduction of social relations. Hence the relationship between the space triad is marked as solid line.

The outer structure includes capital, power and culture that are informed by the seminal work of Lefebvre in relation to the spatial dialectics. Specifically, 'capital' included 'landed capital, commercial capital, finance capital - all play a part in practice' (Lefebvre, 1991, p. 10). It was critical in production practices (Marx, 2011). The nature of capital to pursue circulation and appreciation remains unchanged even though production may shift from the things in space to space itself (Gottdiener, 1993). Given that capital pursues the greatest surplus value, it motivates constant investments in production practices, such as building infrastructures in an urban area (Yeung, 1998), which are often accompanied by the continuous destruction and reconstruction of physical space. Since representational space is a symbolic use of physical space (Lefebvre, 1991), capital may interact with the representational spaces.

Lefebvre claims that space opens to power negotiation as '(space production is) always political and strategic' (Bao, 2003, p. 62). The 'society as a whole continues in subjection to political practice - that is, to state power' (Lefebvre, 1991, p. 8). 'Power' here then is defined as political or governmental enforcement that imposes surveillance and regulates social practices (Elden, 2007; Smith \& David, 1995). Moreover, the representations of space were also argued to subsume power relations (Lefebvre, 1991).

In the Production of Space, culture was argued to occupy the interstices between representations of space and representational space. 'Culture' can intervene the lived space (representational space) via symbolisms and the long Judaeo-Christian traditions (Lefebvre, 1991, p. 40). Culture here refers to the traditional culture that includes 'the customary beliefs, social forms, and material traits of a racial, religious, or social group' (Merriam-Webster, 2019). It can be a distinctive and influential aspect in the production of representational spaces (Nash, 1996). Lefebvre further argued that during the period from the Italian Renaissance to the nineteenth century, 'the representations of space tended to dominate and subordinate the religious origins' (Lefebvre, 1991, p. 40), which implies the possible connection between culture and the representations of space.

To conclude, the present study conceptualises that capital, (political) power and (traditional) culture drive the interplay of the space triad. The negotiation among these constructs fundamentally drives the destination change that has taken on various tourism initiatives. 


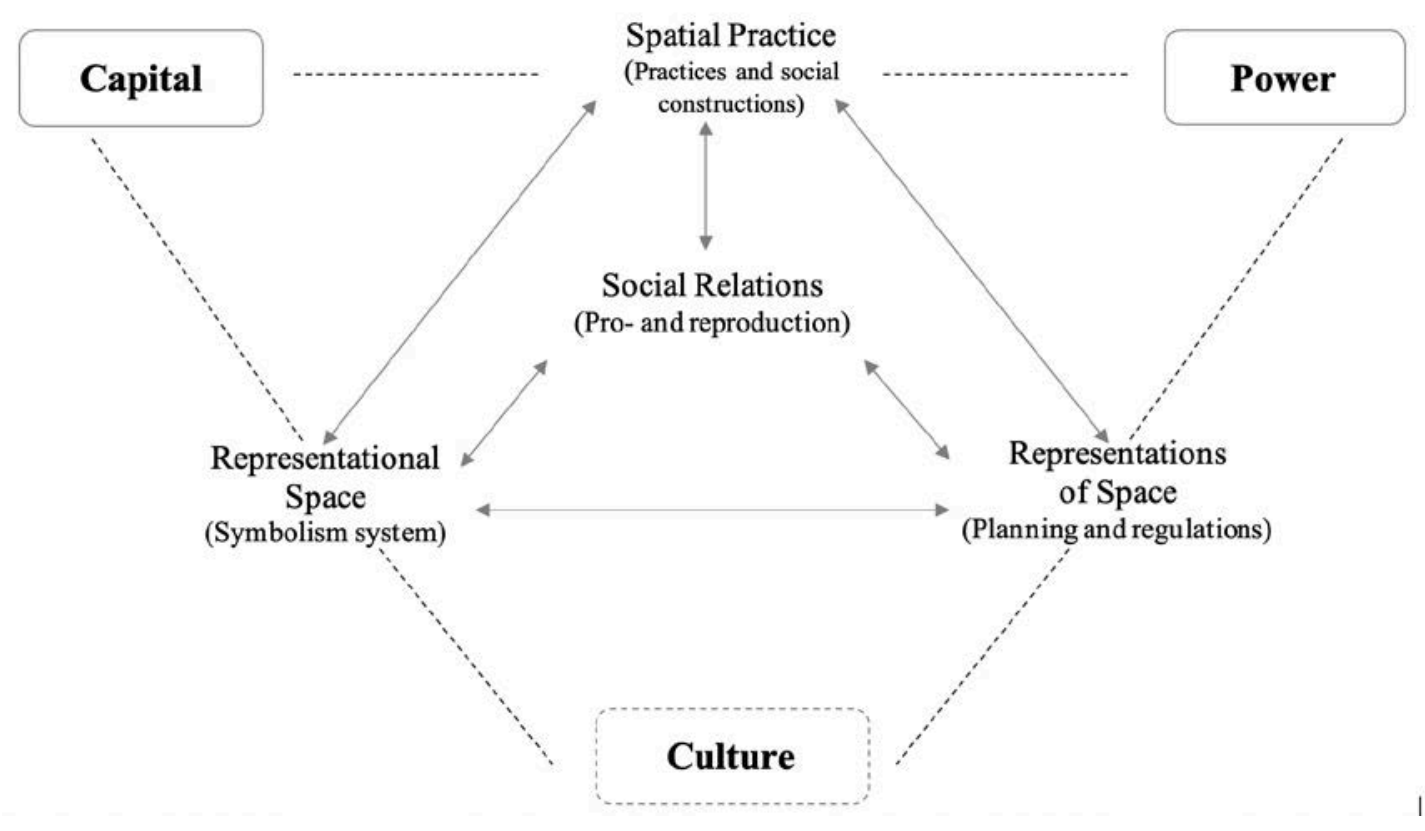

Figure 1. Conceptual framework used for the present research: social space production (constructed based on The Production of Space of Lefebvre [1991])

The social space production framework is helpful in conducting tourism impact research for many reasons. Firstly, it is essentially based on Nietzsche's criticism of the traditional linear historical view (Bao, 2003). Hence, it fundamentally addresses the theoretical deficit of existing tourism impact research. Secondly, the framework focuses on a change 'process' that includes essential components and their dynamic relationships. This perspective can address the problems of fragmentation and the outcome-based approach associated with the current tourism impact research. Thirdly, the framework goes beyond case-based description and opens up a possible theorisation by including new variables, that is, power, capital and culture. Overall, the framework overall provides an alternative lens to understand tourism impact.

\section{Method}

\section{Case introduction 2}

The current study focused on the Huihui and Huixin Villages in Phoenix Town, Sanya, Hainan Province, China. These adjacent villages are established Muslim communities located near the well-known tourist attractions 'Tianyahaijiao' and Sanya Bay. They are found within $10 \mathrm{~km}$ from the Sanya Phoenix International Airport and the city centre (see Figure 2). The two 
villages had a total population of over 8,000 (1,198 households) by the end of 20153. Most of this population are Muslim descendants who immigrated to Hainan from Vietnam by sea during the Song and Yuan Dynasty (A.D. 960 - 1368) to escape from wars and typhoons (Ma, 1998). During the last thousand years the population has grown into the largest Islamic community in South China.

The Hui community's 4 Muslim culture and religious practices are distinctive. They include daily solemn and holy Islam Bangke, five religious services per day, a pork and alcoholfree diet, customary female clothing and Arabic expressions written on the outside wall, such as 'peace' or 'God is the only one'. The two villages have six mosques, namely, the North, Northwest, Ancient and East temples in Huihui; and the South and Nankai temples in Huixin, which have been repeatedly restored throughout history (Xuan, 2011).

The Hui community had limited arable land, making them dependent on fishing since their early settlement. However, fishing has been prohibited since Sanya Bay became a tourist area in 1992. For this reason, tourism has become the only economic production mode for the community. Moreover, the last decades have witnessed dramatic social, cultural and economic changes of the Muslim community (Xuan, 2011), which renders it an ideal case for studying tourism impact.

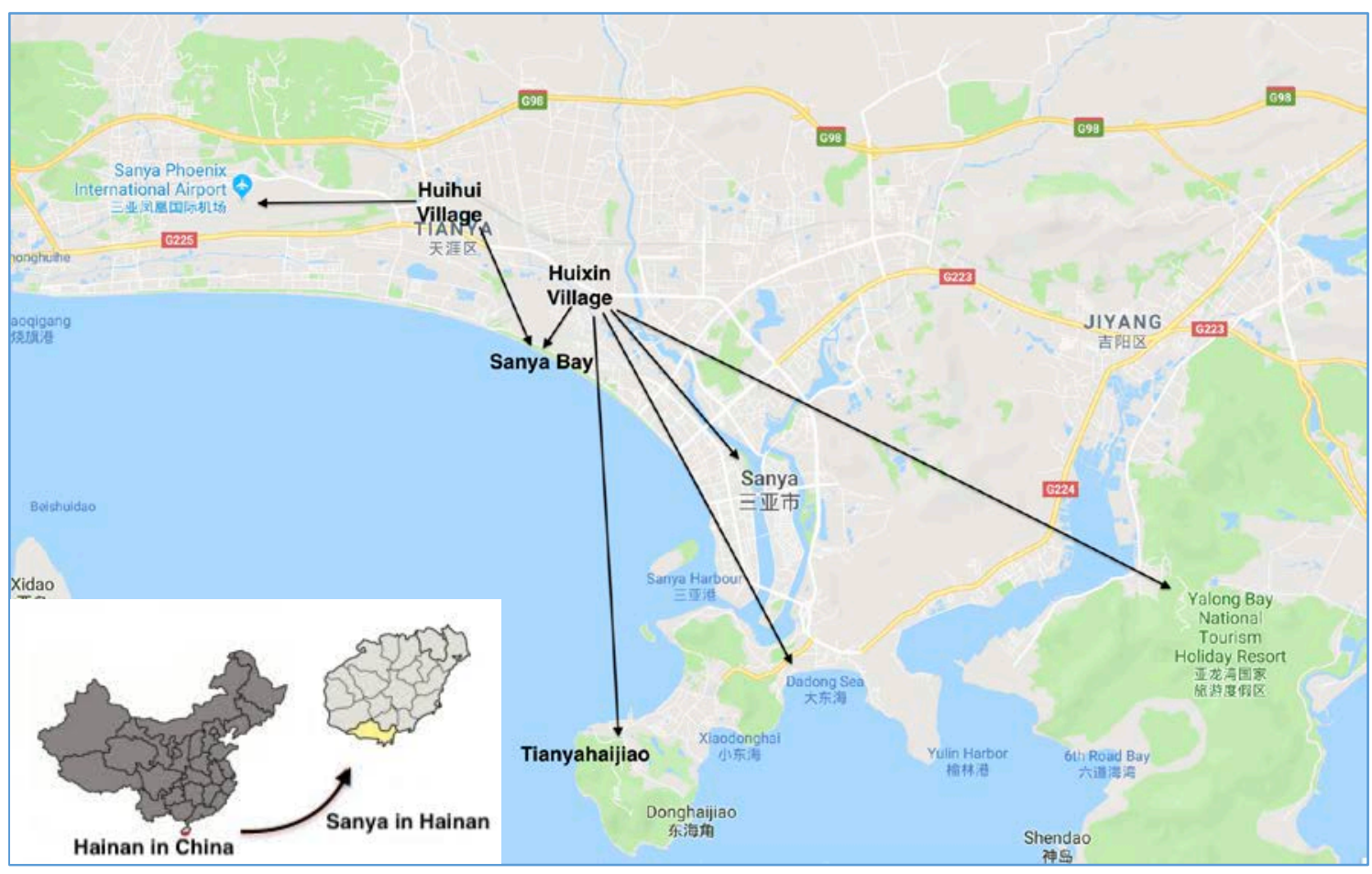

3Source: Economic statistics of Sanya (1994-2015).

4Muslim in China belongs to a specific ethnic group named Hui, the terms Hui community, Hui individuals, and Hui ethnic group in this study all refer to the Muslim community. 


\section{Data collection}

This study was positioned with a constructivist paradigm upon the social space ontology. An ethnological study based on the 'regressive-progressive' approach was followed (Lefebvre, 1991, p. 65), which means 'starting from that present, working our way back to the past and then retracing our steps'(Lefebvre, 1991, p. 66). Investigators first trace back the process of development and then elicit the inner rational along the development process. In this study, the retrospective depiction of community development was applied to reveal the preconditions and driving forces behind the main changes.

The retrospective depiction of development process requires longitudinal fieldworks on the targeted community. From 2003-2018, the leading authors made over nine field trips to the Muslim community, each lasting around 1-2 weeks, making a total of fourteen weeks. All the trips followed slightly different focal points (see Table 1) and they provided an opportunity to observe the longitudinal changes in the two villages.

Table 1. Fieldtrips in the Muslim community in Sanya, Hainan Province

\begin{tabular}{|c|l|l|}
\hline Fieldwork & \multicolumn{1}{|c|}{ Time \& duration } & \multicolumn{1}{|c|}{ Main aim } \\
\hline 1 & $10-21$ March 2003 & $\begin{array}{l}\text { Investigated the changes of ethnic identities and relations of the } \\
\text { Muslim community against the background of modernisation } \\
\text { (Sun, 2004) }\end{array}$ \\
\hline 2 & 5-22 July 2008 & $\begin{array}{l}\text { Explored tourism impacts on ethnic identities and relations (Sun } \\
\text { \& Chen, 2012) }\end{array}$ \\
\hline 3 & $10-19$ March 2009 & Explored the tourism impacts from the space production \\
\hline 4 & $7-17$ September 2012 & perspective (Sun \& Zhang, 2015) \\
\hline 5 & $18-31$ March 2013 & Investigated the impacts of tourism on the elites' power \\
\hline 6 & $13-20$ March 2014 & Investigated the social adaptation of Muslim migrants \\
\hline 7 & 20-29 January 2015 & migrants and local residents \\
\hline 8 & 7-14 March 2016 & \\
\hline 9 & & \\
\hline
\end{tabular}


The data was mainly collected via non-participant observation and in-depth interviews during fieldwork. The authors portrayed themselves as researchers and tourists, such that they interviewed key informants to elucidate the historical trajectory and also admired the Muslim culture from a tourist's perspective. In-depth interviews were conducted to understand the driving forces behind the development of the community. Interviewees included villagers and village governors, who were insiders and key informants, as well as outsiders like migrants (entrepreneurs and residents from other villages) and tourists. Thus, the recording of differing emic and etic views was ensured (Denzin \& Lincoln, 1994). The etic view of the research problem is as important as the emic view so outsiders such as non-Muslims were also interviewed. The etic view could reasonably overcome potential bias provided by the emic view and hence create additional and valuable knowledge (Denzin \& Lincoln, 1994).

This study used purposeful sampling and convenience sampling. The former was used because it provides comprehensive and rich knowledge, in this case the knowledge about the process of community development (Hennink, Hutter, \& Bailey, 2010). The screening question for insiders and entrepreneurs was their length of residency in the community, that is at least one year's residency. Convenience sampling was used on tourists and residents from other villages who provided complementary knowledge.

Interview questions were semi-structured with four main parts: (1) How do you describe the geographic, economic and cultural changes that happened to your villages since your childhood? (2) What are the changes that you have made to your way of living from your childhood? (3) What do you think are the major events that have happened during this period? (4) How did the villagers react at the main turning points over the past decades and why? (E.g. How and why did the two villages participate in the tourism businesses since the Open Policy in 1978?) Other questions were prompted to extend the understanding of the four key questions. Two or three additional interviews were conducted for further confirmation when data collection reached saturation (Denzin \& Lincoln, 1994). Each interview lasted between 30 minutes and 1 hour.

A total of 78 interviewees participated, including 41 residents in the Muslim community, 11 government officials ( 9 of them are also residents in the Muslim community), 22 migrants from other places (16 of them are not Muslim) and 4 tourists (details in Appendix I). Among them, 51 are male and 27 are female, because most government officials and Mosque managers are male. A total of 54 participants were aged 40-75, whereas 24 were between 20 and 39 year's old. Such a diverse range of demographic information was helpful to provide insights to historical space production. Apart from tourists, all participants were involved in tourism related business. 
Substantial secondary data was also collected from local government agencies (Phoenix Town Government, mosques and village committees) and the Internet. They included a book entitled Hui Nationality in Hainan, the Kuran, the promotional videotape and materials of the Phoenix Town and economic statistics from 1994 to 2015. Notably, the book written by an elite in the Muslim community in 2011 provided a comprehensive overview of Hui Villages (Xuan, 2011) and served as an important supporting historical reference.

Data reliability issues were examined. One is the recollection bias resulting from recalling long past memories. This bias was minimised by triangulating different sources of information provided by the interview participants and secondary data (Flick, 2004). Moreover, given that the data was collected and analysed in Chinese, language bias may arise when translating it into English. To minimise this, the data was kept and analysed in Chinese until the reporting stage. Identified themes and direct quotes were translated into English and then back to Chinese by the researchers to ensure the accuracy in language (Lam \& Hsu, 2004). In addition, member checking on the interpretive and descriptive accuracy was conducted during the interview process by restating and summarizing information achieved to the participants to ensure the data validity (Harper \& Cole, 2012).

\section{Data analysis}

Content analysis, which refers to a method to make valid reference from written, verbal or visual messages (Cole, 1988), was adopted. In contrast to other techniques like thematic analysis which suits for analysing narrative materials and life stories, content analysis aims to achieve exploratory work of an unknown phenomenon like the present study (Vaismoradi, Turunen, \& Bondas, 2013). By repeatedly getting through the various texts, constructive codes and themes, as well as inner relationships could be obtained.

Content analysis can be used in an inductive or deductive way (Elo \& Kyngäs, 2008). The present study used the deductive content analysis with three main steps: preparation, organising and reporting data (Elo \& Kyngäs, 2008). In the preparation stage, the authors transcribed the interviews in Chinese. Participants' names were coded according to their interview number, gender and age to ensure anonymity. For example, F1F40 means a 40-yearold female who was the first interviewee in the first trip. In the organising stage, the first step for deductive content analysis is to develop an analysis matrix. Although this study adopted the social space production framework, a relatively flexible structured matrix (see Appendix II) was used to capture any unexpected construct (Stemler, 2001). Transcripts and other materials were gone through for vivo and vitro codes, which were further grouped and categorised into themes according to the matrix. NVIVO 10 was used for coding process. 


\section{Findings}

\section{Tourism development process of the Muslim community in Sanya}

Tourism development of the Muslim community benefited from the development of Sanya. Figure 3 shows the four phases of tourism development in the community, which include budding, beginning, stable increase and rapid growth stages. These phases correspond to the major turning events and tourists' arrivals in Sanya. The budding stage took place before the implementation of the Chinese Open-Door Policy in Sanya. The life of Hui community was then dominated by fishing and farming, which was described as difficult.

The introduction of the Open-Door Policy in China in 1978 marked the beginning stage of the tourism development for Hui community that lasted until 1993.This stage was fostered by numerous political and economic events. One was the establishment of Hainan as a province and the upgrade of Sanya to a prefecture level city in 1988. These changes attracted direct investment from the central government in Hainan, particularly Sanya. A remarkable investment was the development of Yalong Bay into a tourism resort in 1992. Approximately one million tourists visited Sanya in 1993, which boosted the tourism and hospitality market. Hui residents began to take advantage of the opportunity by engaging in tourism-related businesses, including transportation services and simple retailing at these tourist attractions. Consequently, the Muslim community went through a change from a single production mode of fishing and farming to a diversity that included tourism businesses.

The stable increase stage was between 1994 and 2007, following the construction of the Sanya Phoenix International Airport in 1994 and the development of Sanya Bay in 1998. A total of 5.4 million tourists visited Sanya in 2007, over four times the 1.3 million visitors in 1997. However, the development of hospitality facilities in the established attractions (like Yalong Bay and Sanya Bay) was falling behind the fast growth but had to push tourists to surrounding areas. Those near the Sanya Phoenix International Airport and the city centre benefited the most. Consequently, the Muslim community started to operate family inns as tourists flooded to their villages. As a result, Hui's engagement with tourism progressed from being only subordinate to Sanya to a standalone tourism centre.

The rapid growth of the Muslim community took place during the past decade, following the implementation of the International Tourism Island Policy in 2008. It aimed to turn Hainan Province into an international seaside resort. Consequently, considerable investment was attracted to Sanya particularly to the real estate sector. Investors favoured the pleasant climate of Hainan which had an average annual temperature between 23 and 25 degrees. Increasing number of visitors from cold northern China visited here for winter 
holidays. Under this wave, the Hui community was becoming an increasingly popular destination for Muslim investors and tourists taking advantage of its cultural and religious similarities. In 2012 over 10,000 Muslims from Northern China, who were called 'migrant birds', stayed here for winter holidays. In 2017 the number grew to approximately 20,000. As more tourists were coming in, it became imperative for the service providers to accommodate the tourists' sociocultural preferences into catering, transportation, handcrafts and hospitality facilities.

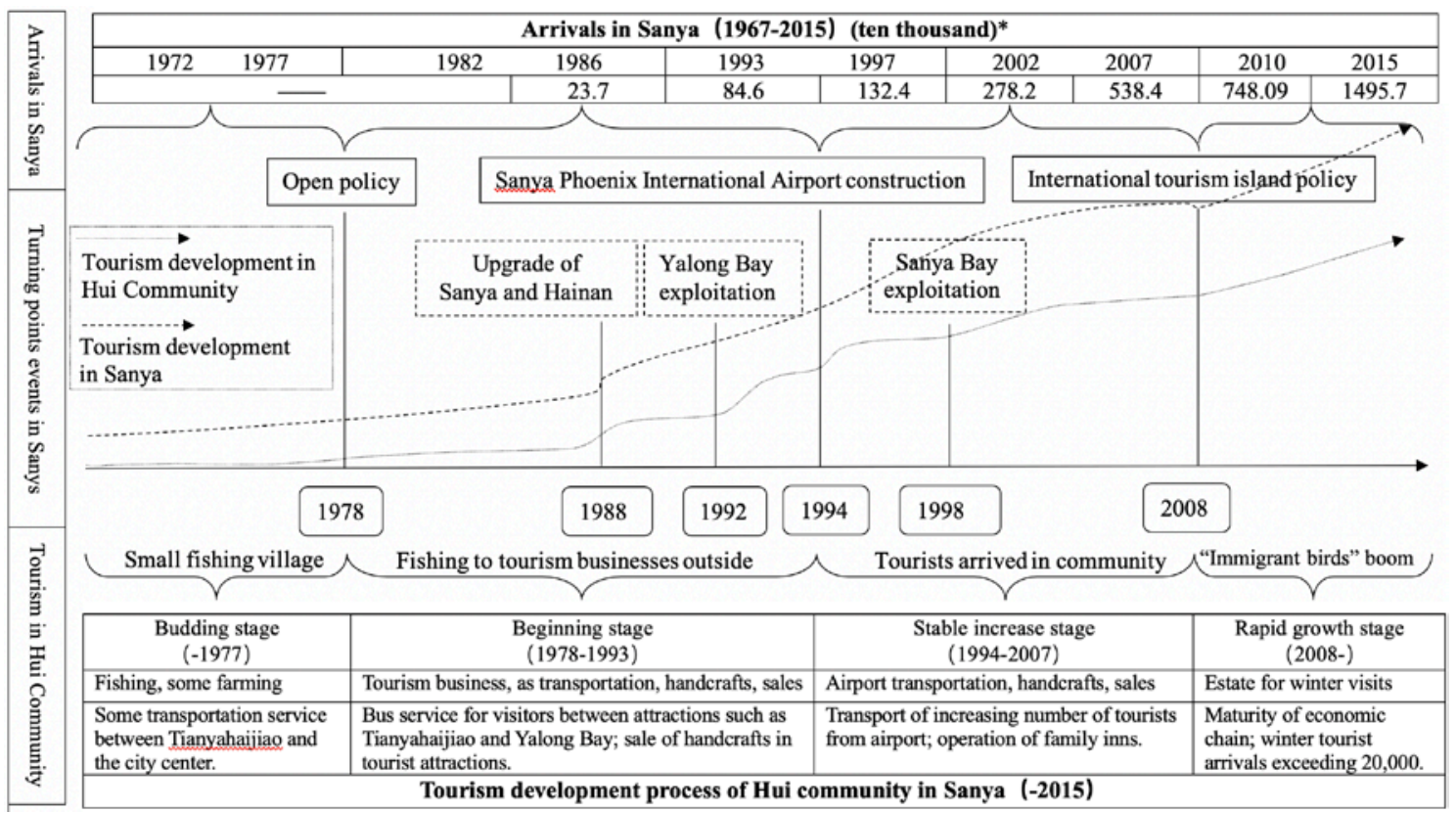

*Source: Retrieved from the economic statistics of Sanya (1994-2015)

Figure 3. Tourism development process of the Muslim community

Throughout the four phases, the space of the Muslim community went through major changes and production. This process included the emergence of various handcraft vendors, the normalisation of tourism transportation, landscape changes, religious communication and mosque reconstructions. One marked change was a result of the real estate construction boom. With over 50 high-rise buildings being constructed, the two villages were transformed instantly into a mixture of urban and rural landscape. Some people found it a modernised city: 'following the (real estate) development, life here is just the same as that in my home city' (F23F40-a Muslim from Gansu). However, some people insisted that 'it is still a small village due to the unhealthy and messy development, such as the mixed styles of houses' (S7M55-a resident of the Han group). Many streets in the community featured high-rise buildings on the left and tileroofed houses on the right. The next sections focus on the real estate boom to trace the logic of space production in the Muslim community. 


\section{Capital: Invisible hand with limitations}

The building boom catalysed by capital investment in both Sanya and Hui has been formidable over the recent decade. The interaction between capital and building practices amongst the Muslim community evolved through three main stages: preparation, competition, and collaboration. The preparation period (before 1994) witnessed substantial government/public investment in the construction of attractions in Sanya and infrastructure improvement both outside and inside the Hui community. Many roads were improved or reconstructed along with the development of Yalong Bay and the construction of the Sanya Phoenix International Airport. These developments accelerated tourism in Sanya and tourism businesses for the Muslim community. Hui residents abandoned fishing and farming for the opportunities created by tourism. The improved productivity and economic conditions further funded the infrastructure development inside community, which in turn prepared for the hotel building boom and expansion of the tourist market.

The competition period occurred during the stable increase stage, when tourism reception encroached onto the Muslim community. External corporate capital from well-known real estate groups, such as Wanda, Country Garden and the Evergrande began to appear in Sanya and Hui community. To accommodate emerging tourists in the community, the external capital from inland hotel groups and the internal capital from Hui villagers competed for the space and production materials in the community to build hotels. The two villages thus saw substantial constructions of hotels, such as the Jiulixiang Hotel, Yilaishun Hotel and Huafang Hotel, as well as other hospitality facilities. The capital competition and corresponding hotel building boom induced considerable spatial changes in the Muslim community's landscape: the main roads were surrounded by high-rise buildings.

The collaboration period coincided with the rapid development stage and featured a considerable amount of private investment in real estate construction made jointly by outside Muslims and local Hui residents. Many villagers used their lands or savings to cooperate with investors from other Hui regions of China to build accommodation for winter visitors: 'Most people in our villages have land but lack money. Relying on their small businesses they would never be able to accumulate enough money to build their own houses. Hence, through the reliance on outside Muslims to finance the building of the houses thereby making money and improving our living conditions we can kill two birds with one stone' (F10M50 - a local mosque employee). To attract investors and tourists, the local residents compromised in their architecture, resulting in buildings with generic exterior appearances and hotels in varied styles, such as hostels and timeshare apartments. 
Capital is an inherent driving force in the whole production process of 'spatial practices', and its nature is to maximise the value of a possession. The three stages outlined above illustrate that capital performed its vital role in two ways: as an active accelerator of production (production logic) and as a passive objective of production (appreciation logic). The production logic means the capital was actively used to speed up the production practices. Tourism development was initially a top-down strategy for improving the economic productivity and local life in Hainan. To achieve this goal, it was essential to improve the infrastructure and create a productive environment. A large amount of Government capital flowed into the city to effect this change, resulting in effective production practices in Sanya, an improved environment, heightened productivity and new production relations for the Muslim community: 'Undoubtedly people in the villages have more friends than before, including some out-of-town because of the business' (S3M22-the son of an owner of a local hotel).

The appreciation logic posits that capital is the final target of production. As Marx (2011) revealed, the circulation of capital never ends. New social relations and, thus, new spatial practices (i.e. tourism development) aim to achieve further capital appreciation. For example, the building boom in the Hui community was the result of joint ventures between the accumulated internal capital and the external capital (corporate and private) to achieve higher surplus capital value. The pursuit of additional capital was the primary cause of Hui community's transformation from a self-sufficient fishing economy to a promising service economy. In this appreciation logic, attractions and infrastructures constructed in Sanya and the various accommodations in the Muslim community were used as 'production materials' for generating additional benefits.

The circulation of capital in the community was not unscrupulous, and many of the new buildings maintained Muslim cultural signs. Arab logos or words and 'Dome and Moon' decorations can still be found in every new building, but they have become internal displays. Arabic words were no longer displayed on the walls outside; instead, they were moved to personal rooms to suit the aesthetic preferences of tourists from other cultural backgrounds. This change illustrates the collaboration between the capital and representational space of the community. Moreover, the capital sources were largely constrained by local culture to be Muslim investors: 'There are too many high buildings with 7-8 stories in our village, at least 70 to 80. Most of them are financed by outsiders and co-constructed with the locals. Certainly, those outsiders are all Muslims from other parts of China, like Xinjiang and Gansu, et al.' (F11M49-a local resident with a family hotel).

In addition, the Muslim cultural codes had impacts on the capital distribution. In accordance with the doctrine of helping others, cash given to newly married couples in the local 
community has been increasing significantly every year. Young newlyweds can receive 1-2 million yuan from the villagers, especially rich ones, which they use to invest in constructing guesthouses to improve their living conditions. This act of helping others contributes to capital redistribution and may positively alleviate the segregation between the rich and the poor. Thus, 'the good relationship among the villagers remained over time' (F30M30-a local resident).

\section{Power: Control and being tactical}

The production and construction practices in Muslim community has also been influenced by power bodies in the form of numerous planning and regulations imposed by the Chinese government since 1988 .

The planning set guidelines for production practices in the Muslim community. The Master Planning of Sanya (1995-2010) is an important turning point that established the key tone of tourism development in the whole area. With the aim to 'construct Sanya as a modern international coastal city', the master plan introduced several detailed plans, such as the development of Yalong Bay, urban infrastructure, the Sanya Phoenix International Airport and Sanya Bay. Overall, the whole city Sanya was regulated to develop tourism industry. Consequently, the Hui community transformed its production and construction including the real estate boom into tourism focused.

Rules and regulations normalised construction practices. The International Tourism Island Policy in 2008 propelled the building boom to expand horizontally and vertically. The stories of the newly built flats went increasingly high in Sanya and the Hui community, with most of them in Sanya reaching 12 stories or above. Interestingly, most buildings within the two villages were around 8 stories: 'The government regulated the building height in our villages to be less than 8 stories because the airport is nearby. A 12-story flat along the Phoenix Road was destroyed days ago. Some investors challenged the regulation, but neither the Muslim migrants nor tourist intend to buy at the risk of breaking the regulations' (F31M60- a local resident).

The implementation of government power was not always straightforward due to possible resistance from the Muslims. This forced a more tactful or flexible fashion of implementing blanket policies in the Muslim community. For example, the scope of the community plan in the Master Planning of Sanya (1995-2010) excluded the Muslim community. This is because 'it was difficult to control the directions of the two villages because of their special culture' (S1M40-a staff of Phoenix Town Government). The Master Plan 'initially planned to build the Muslim square of this community into an Islamic street that mainly serves Muslim tastes' (F12M35-a government staff in Phoenix Town). It faced strong resistance from the two villages, because they 'do not want to commercialise their faith or be 
forced to sell pork, which is against their religion' (F10M50-a local mosque employee).

Consequently, the planning autonomy had to be returned to the hands of the Hui community.

Another example of the 'tactical' power is manifest through the implementation of the Rural Land Contract Law of the People's Republic of China (2002) and the Management of Rural Land Circulation of the People's Republic of China (2005). Both laws prohibited trading in flats that are built on rural homesteads because of no proper land registry. The government however turned a blind eye to the trading as long as the flat construction did not hinder the operation of the Sanya Phoenix International Airport. Behind this was economic benefits brought by flat trading: 'How to say; the government is not very strict. They are clever. Tens of millions were invested in buildings without proper land registry. Otherwise, no one would invest' (S4M45-a hotel manager from other provinces).

From Lefebvre's view, space has a political dimension in that planners and engineers construct social order through plans and regulations. The government has the power to drive the production of 'representations of space' in the Muslim community. Through the incentivised policies, the government encouraged capital investment and regulated production practices. However, it should be noted that the government power was challenged by Muslims' collective practices. Consequently, the power had to be tactical to ensure success in economic development for Sanya.

\section{Culture: Inward-oriented consolidation and outward-oriented negotiation}

The Muslim religious culture and its network development were also shown as an important dimension in the community space production. For example, the renovation and reconstruction of six mosques were the priorities during the building boom. The Ancient Temple was reconstructed in 2010 with a budget of 7 million yuan. In 2012, a grand temple appeared in the centre of Huihui Village, which was several times larger than what it was before. It was done in the distinct Arabic style, with a minaret pointing towards the sky on four corners, the moon decoration on top and carved patterns inside the hall. It is phenomenal in its own purpose, but it demonstrated the Muslim's strong cultural influence in negotiating the community's space. This influence is represented by inward-oriented and outward-oriented dimensions, as discussed below.

These newly built Mosques have helped to consolidate Islam culture inwardly. As the clandestine or underground side of the Muslim community, culture is symbolised by signs and codes that may appear on houses and mosques, thereby producing a community's 'representational space'. Spiritually and practically, these symbols consolidate cultural identity by providing a consensus for religious communication and practices (e.g. daily prayer and 
traditional festivals): 'Some traditional festivals, such as Ramadan, Eid al-Fitr and Eid al-Adha, are still celebrated every year as the biggest event in our villages' (F25M30-a local resident).

Moreover, the mosques enhanced the religious relations of the Hui community with other Muslim groups through socioeconomic production and biological reproduction. For example, the Ancient Mosque, which cost 7 million yuan to build in 2010, 'was funded by the Hui nationalities all over the world' (F36M63-a local resident), so were the reconstructions of the South Temple in Huixin and the North Temple in Huihui. These actions strengthened the connections of the Hui community in Sanya with Muslims worldwide. They also encouraged transregional marriages within Muslims in China, including a Muslim (S16M42-a Muslim from Liaoning) from Liaoning Province who married a woman in Huihui Village. Moreover, the Hui residents revealed that four international Muslim marriages with other Arab countries have occurred in the last decade. These practices enhanced the religious order in Hui community: 'The identity of our community has been enhanced a lot by communicating with other Hui groups in northern China and worldwide. Otherwise, we would have been converted into Chinese' (F36M63-a local resident).

Mosques also represent an autonomous cultural organisation for outward negotiation. Although the state and central governments impose macro-control, mosques have imams and mosque committees who have absolute influence over the community's daily life: 'The villagers make little communication with the government. We mainly have contact with religious organisation' (S2M50- a local mosque staff). Imams were described in an interview as 'the leaders of Mosques, and generally individuals with ability and leadership' (S37M43-a safety guide in the village). They function as local knowledge brokers in negotiation with 'representations' of planning and regulations, such as justifying the rights for planning the Muslim square. Managing the two Hui villages was relatively difficult for the government because of the endogenous cultural system.

Admittedly, the Muslim culture does not always outweigh the logic of administrative power for control and the logic of capital for appreciation. For instance, the Muslim community in Sanya was suppressed by the government during the Qing Dynasty. Some residents were Chinesised or changed to $l i$ by that time. To date, due to accelerated tourism development, religious customs like the daily prayers and Ramadan sometimes gave way to tourism business hours. One of the beliefs is that 'Prayer is not to regulate us. You can pray in other times instead of in regular hours' (F10M50- a local mosque staff).

The Islamic religious tradition has shaped the community's representational space in production and reproduction practices for over 1,000 years. Amidst all of these, the Muslim culture played an important role in balancing the power of the state government and the 
invasion of capital investment, thus maintaining Muslim religious values and traditions through a religious management system.

The above discussion regarding social space production is summarised in Figure 4. As can be seen, it is not tourism, but the logic of capital, power and culture which served as the main drivers behind the space production. The production and appreciation logic of capital promoted spatial practices (e.g. tourism production and house construction). The expression and adaptation of power assigned the social orders (representations of space) through regulation and planning. The traditional Muslim culture shaped the representational space through mosques and traditions. These synergic effects facilitated the production of space of the Hui community in the space triad and the changes in social relations.

The performance of the logic also has limitations. The circulation of capital was constrained by the representational space (e.g. cultural codes). The control of administrative power could be challenged by resistance from local practices. The function of Muslim culture confronted negotiation from representations of space (e.g. regulations). These types of constraints (gaming effects) could result in changes, tactical control and revisions of the corresponding space triad. The cooperation of these synergic effects and gaming effects finalised the space triad that enacted the production and reproduction of this Muslim community.

While this framework is rooted in explaining social changes in a generic context, space production in the tourism context shows its own characteristics. The space production process is relatively fast in a tourism community because capital can react promptly to tourism development due to its low entrance barriers. For example, the government, the corporations and private investors accessed tourism development opportunities with little technical barriers, followed by substantial constructions of tourism and hospitality facilities. Meanwhile, the administrative power should impose well-rounded planning and regulations on the community because the tourism industry involves different sectors. When the production mode in the Hui community changed dramatically from fishing to tourism businesses, new social production order was reconstructed. In addition, culture plays a dual role in destination space production due to the resource-based nature of tourism. Culture, at the same time acting as an important resource that attracted tourists, was consumed by tourists to change. 


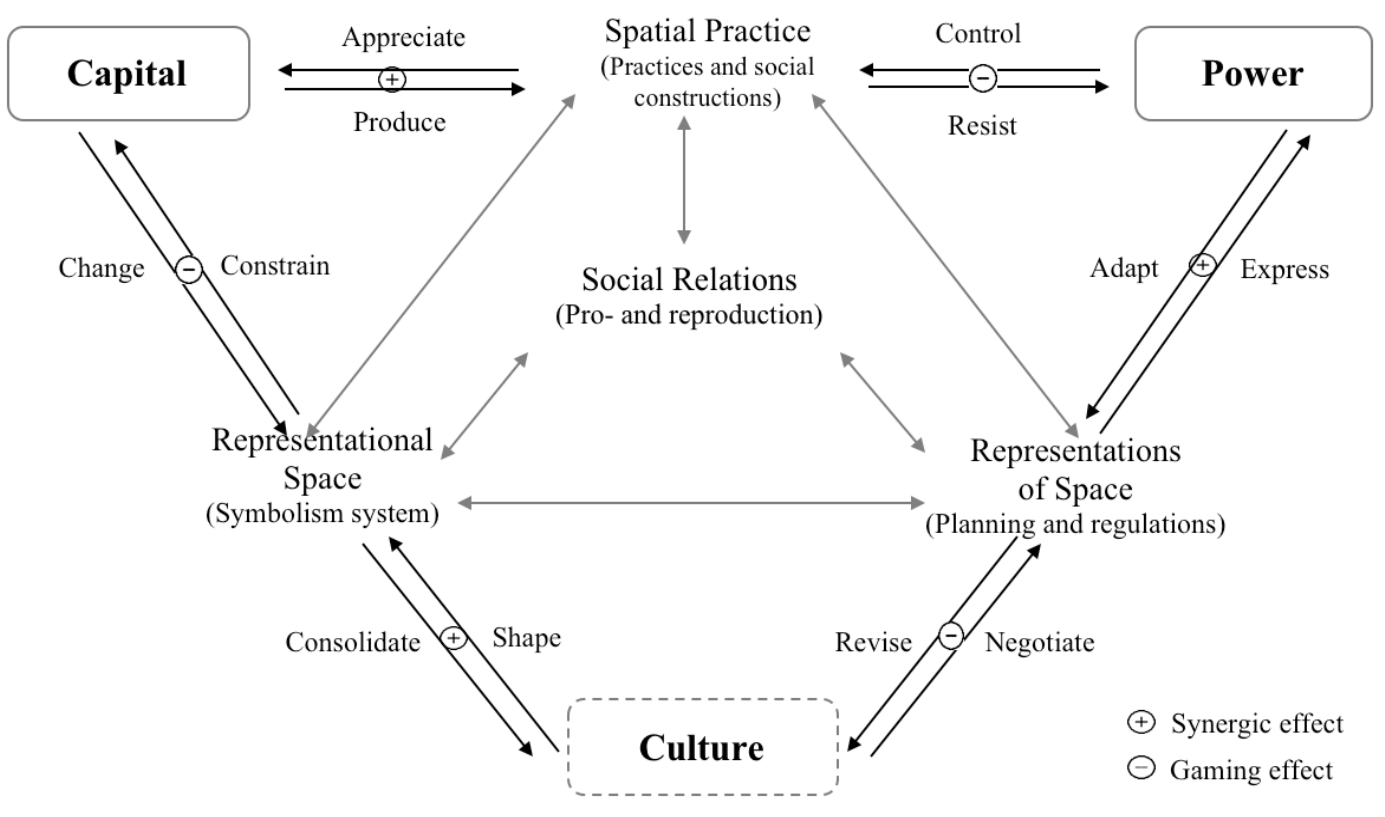

Figure 4. Inner logic of social space production of the Muslim community

\section{Conclusion and discussion}

This study aims to understand the process of tourism impact from the perspective of social space production theory. A theoretical framework has been constructed to describe destination change as a dynamic process of interaction and production amongst the space triad, with capital, power and culture as the underlying mechanisms.

Capital is an inherent logic of space production and functions in two main ways: production logic as an active accelerator and appreciation logic as a passive objective (discussed in the results). Capital was initially introduced to accelerate the 'spatial practices' for tourism production. Accumulated capital continues to be invested in production practices to gain further capital appreciation. During this process, the space of the host community also became part of the production materials (e.g. hotels), followed by substantial landscape changes.

Space production is deeply rooted in the political sphere. The central Chinese government plays an important role in exerting power to control local development by enforcing policies and regulations. They represent the 'representations of space.' On the one hand, power enhances and controls capital circulation and accumulation in the Muslim community. On the other hand, the implementation of political power became a tactical approach to counteract the challenges from the Muslims' practices. The result of this tactical implementation may be the adaptation of the 'conceived' space by the government.

Muslim culture is also an important factor in space production as it constitutes the 'representational space'. Culture sustains and strengthens the community's fundamental order through Mosques and religious organisations. This autonomous cultural management system 
negotiates with the influence of power to exert constrains on capital circulation. Sometimes, culture also gives way to both capital and power to change the 'representational space' and further revise the culture system.

The theoretical framework outlined above bridges the gaps in tourism impact research. Previous tourism impact research advanced incrementally because of the outcome-based approach and the descriptive manner by which they were conducted (Buzinde \& ManuelNavarrete, 2013; Kordel, 2014). This framework based on spatial ontology and epistemology provides a synthesised and dialectic theoretical perspective to reveal the inner logic of destination changes. It suggests that tourism should not be blamed for the sin of 'impacts' on host communities but the accelerator of the whole process. The interaction of capital, power and culture propels the production of space.

This study also contributes to a more theoretical interpretation of destination changes. According to Hegel's dialectics (Mueller, 1958), the final stage for science is 'synthesis', which distils ideas for understanding the nature of the world. The destination space production framework in the present study breaks the limitations of focusing on describing varying change outcomes in tourism communities and highlights the underpinning mechanisms. It advocates indepth research to explore the nature of social changes for more united and robust knowledge creation. In particular, capital, power and culture are effective in every period of history and in different regions. They can unite various relevant contextual factors identified by the existing studies in tourism destinations, such as place identity (Wang \& Chen, 2015), economic level (Cárdenas-García et al., 2015) and tourism participation (Woo et al., 2018). Consequently, the destination space production framework theorises the process of a destination's changes.

While space production theory is insightful, it is imperative for future social science research to explore its application. This study shows that the social space production theory provides an alternative but pertinent lens to study tourism impact. Considering that the theory was rooted in explaining social changes, any changes in tourism and hospitality could refer to it. For example, it can be applied to tourism cultural studies, tourists' changing motivation and preferences of destinations, and evolving structure of hotel business. This study took a longitudinal observation of the Muslim community, but it could benefit from a lengthier fieldwork duration than that completed in this study. Fieldtrips were mainly conducted in other periods of the year apart from winter (October to December). It would be ideal to sample all times of a year so a better observation of Muslim practices can be achieved. In addition, future research can attempt to develop the scales included in the model so that the identified relationship could be numerically verified.

\section{Acknowledgement}


This work was supported by the Major Project of The National Social Science Foundation, 'Conservation and Utilization of Traditional Ethnic Minority Villages in Southwest China' (15ZDB118 ) ; and the National Natural Science Fund, 'The Production of Social Space in the Process of Community Participation in Tourism Development: Interdisciplinary empirical study of Multiple cases’（

41171124/D010202).

\section{Appendix I Information of participants}

\begin{tabular}{|c|c|c|c|c|c|}
\hline Code & Gender & Age & Role & Year* & Ethnicity \\
\hline F1M30 & Male & 30 & Merchant in the Muslim community & 1 & Han \\
\hline F2F20 & Female & 20 & Resident and employee in the community & 20 & Hui \\
\hline F3F21 & Female & 21 & Employee in the community & $7 \mathrm{~m}$ & Han \\
\hline F4M40 & Male & 40 & Host of a hostel in the community & 14 & Han \\
\hline F5M45 & Male & 45 & Resident and landlord of a supermarket & 45 & Hui \\
\hline F6F31 & Female & 31 & Resident and merchant in the community & 31 & Hui \\
\hline F7M46 & Male & 46 & Resident and merchant in other cities & 46 & Hui \\
\hline F8M75 & Male & 75 & Resident & 75 & Hui \\
\hline F9M70 & Male & 70 & Resident & 70 & Hui \\
\hline F10M50 & Male & 50 & Resident and the manager of a mosque & 50 & Hui \\
\hline F11M49 & Male & 49 & Resident and host of a local hostel & 49 & Hui \\
\hline F12M35 & Male & 35 & Officer of Fenghuang Town & 6 & Han \\
\hline F13M50 & Male & 50 & Resident and driver for transportation & 50 & Hui \\
\hline F14M25 & Male & 25 & Resident and son of an imam & 25 & Hui \\
\hline F15F18 & Female & 18 & Resident and retail merchant & 18 & Hui \\
\hline F16M50 & Male & 50 & Resident and village committee member & 50 & Hui \\
\hline F17F34 & Female & 34 & Merchant in the Muslim community & 1 & Han \\
\hline F18M47 & Male & 47 & Merchant in the Muslim community & 7 & Hui \\
\hline F19M46 & Male & 46 & Resident and village committee member & 46 & Hui \\
\hline F20F25 & Female & 25 & Resident and housewife & 25 & Hui \\
\hline
\end{tabular}




\begin{tabular}{|c|c|c|c|c|c|}
\hline F21M38 & Male & 38 & Resident and merchant in Tianyahaijiao & 38 & Hui \\
\hline F22F33 & Female & 33 & Merchant in the Muslim community & 3 & Hui \\
\hline F23F40 & Female & 40 & Merchant in the Muslim community & 1 & Hui \\
\hline F24M70 & Male & 70 & Resident and host of local hostel & 70 & Hui \\
\hline F25M30 & Male & 30 & Resident and merchant in Sanya & 30 & Hui \\
\hline F26M26 & Male & 26 & Resident and merchant out of the community & 26 & Hui \\
\hline F27F42 & Female & 42 & Resident and merchant in the community & 42 & Hui \\
\hline F28F50 & Female & 50 & Resident and retail merchant & 50 & Hui \\
\hline F29F23 & Female & 23 & Resident and retail merchant & 23 & Hui \\
\hline F30M30 & Male & 30 & Resident and driver for transportation & 30 & Hui \\
\hline F31M60 & Male & 60 & Resident and retail merchant & 60 & Hui \\
\hline F32M50 & Male & 50 & Merchant in the Muslim community & 12 & Hui \\
\hline F33F42 & Female & 42 & Resident and retail merchant & 42 & Hui \\
\hline F34F31 & Female & 31 & Resident and retail merchant & 31 & Hui \\
\hline F35M47 & Male & 47 & Resident and employee of a travel agency & 47 & Hui \\
\hline F36M63 & Male & 63 & Resident & 63 & Hui \\
\hline $\mathrm{S} 1 \mathrm{M} 40$ & Male & 40 & Resident and officer of Fenghuang town & 40 & Hui \\
\hline $\mathrm{S} 2 \mathrm{M} 50$ & Male & 50 & Resident and village committee member & 50 & Hui \\
\hline S3M22 & Male & 22 & Resident and son of a hotel landlord & 22 & Hui \\
\hline S4M45 & Male & 45 & Manager of a hotel & 3 & Han \\
\hline S5F25 & Female & 25 & Resident and retail merchant & 25 & Hui \\
\hline S6M46 & Male & 46 & Driver for transportation around & 1 & Han \\
\hline S7M55 & Male & 55 & Merchant in the Muslim community & 6 & Han \\
\hline S8F25 & Female & 25 & Merchant in the Muslim community & 1 & Han \\
\hline S9M57 & Male & 57 & Resident and village committee member & 57 & Hui \\
\hline S10M45 & Male & 45 & Officer of Fenghuang town & 10 & Han \\
\hline $\mathrm{S} 11 \mathrm{~F} 50$ & Female & 50 & Tourist & $3 \mathrm{~d}$ & Korean \\
\hline
\end{tabular}




\begin{tabular}{|c|c|c|c|c|c|}
\hline S12M46 & Male & 46 & Resident and officer of Fenghuang town & 46 & Hui \\
\hline S13M41 & Male & 41 & Manager of a hotel in the community & 8 & Han \\
\hline S14F40 & Female & 40 & Tourist & $4 \mathrm{~m}$ & Hui \\
\hline S15F43 & Female & 43 & Resident and host of a local hostel & 43 & Hui \\
\hline S16M42 & Male & 42 & Driver for transportation & 1 & Hui \\
\hline S17F39 & Female & 39 & Resident and retail merchant & 39 & Hui \\
\hline S18M37 & Male & 37 & Retail merchant with other Hui residents & 6 & Hui \\
\hline S19M40 & Male & 40 & Retail merchant with other Hui residents & 3 & Han \\
\hline S20M45 & Male & 45 & Resident and retail merchant & 45 & Hui \\
\hline S21F45 & Female & 45 & Resident and retail merchant in Sanya Bay & 45 & Hui \\
\hline S22F55 & Female & 55 & Resident and retail merchant in Sanya Bay & 55 & Hui \\
\hline S23M43 & Male & 43 & Manager of a hotel in the Muslim community & 5 & Han \\
\hline S24M32 & Male & 32 & Employee of the Sanya Phoenix Airport & 2 & Han \\
\hline S25M23 & Male & 23 & Resident & 23 & Hui \\
\hline S26F46 & Female & 46 & Resident and retail merchant in attractions & 46 & Hui \\
\hline S27F29 & Female & 29 & Resident and retail merchant in attractions & 29 & Hui \\
\hline S28F40 & Female & 40 & Retail merchant with other Hui residents & 5 & Han \\
\hline S29F47 & Female & 47 & Retail merchant with other Hui residents & 6 & Han \\
\hline S30M45 & Male & 45 & Driver for transportation & 5 & Han \\
\hline S31M49 & Male & 49 & Resident and host of a local hostel & 49 & Hui \\
\hline S32M50 & Male & 50 & Resident and officer of Fenghuan Town & 50 & Hui \\
\hline S33F40 & Female & 40 & Resident and host of a local restaurant & 40 & Hui \\
\hline S34F60 & Female & 60 & Resident and retail merchant & 60 & Hui \\
\hline S35M50 & Male & 50 & Resident and village committee member & 50 & Hui \\
\hline S36M55 & Male & 55 & Resident and retail merchant & 55 & Hui \\
\hline S37M43 & Male & 43 & Resident and village committee member & 43 & Hui \\
\hline S38M39 & Male & 39 & Resident and manager of Mosque & 39 & Hui \\
\hline
\end{tabular}




\begin{tabular}{|l|l|l|l|l|l|}
\hline S39M70 & Male & 70 & Tourist & 5 & Hui \\
\hline S40M28 & Male & 28 & Resident and retail merchant & 28 & Hui \\
\hline S41M65 & Male & 65 & Tourist & 1 & Hui \\
\hline S42M40 & Male & 40 & Merchant in Muslim community & 3 & Han \\
\hline
\end{tabular}

* Years of stay in or work together with the Muslim community. 


\section{Appendix II A semi-structured matrix for categorisation}

\begin{tabular}{|l|l|l|l|l|l|}
\hline $\begin{array}{l}\text { (1) How did you describe } \\
\text { the geographic, economic } \\
\text { and cultural changes that } \\
\text { happened to your villages } \\
\text { since your childhood? }\end{array}$ & $\begin{array}{l}\text { Geographic } \\
\text { background }\end{array}$ & $\begin{array}{l}\text { Cultural } \\
\text { background }\end{array}$ & $\begin{array}{l}\text { Economic } \\
\text { background }\end{array}$ & $\begin{array}{l}\text { Development } \\
\text { history }\end{array}$ & $\cdots$ \\
\cline { 2 - 7 } $\begin{array}{l}\text { (2) What were the changes } \\
\text { that you have made to your } \\
\text { way of living from your } \\
\text { childhood? }\end{array}$ & $\begin{array}{l}\text { Spatial } \\
\text { practices }\end{array}$ & $\begin{array}{l}\text { Representations } \\
\text { of space }\end{array}$ & $\begin{array}{l}\text { Representational } \\
\text { space }\end{array}$ & $\begin{array}{l}\text { Social } \\
\text { relations }\end{array}$ & $\cdots$ \\
\cline { 2 - 7 } $\begin{array}{l}\text { (3) What do you think } \\
\text { were the major events } \\
\text { happened during this } \\
\text { period? }\end{array}$ & $\begin{array}{l}\text { Major } \\
\text { (4) How did the villagers } \\
\text { react at the main turning } \\
\text { points over the past } \\
\text { decades and why? }\end{array}$ & Capital & Power & Culture & $\cdots$ \\
\hline
\end{tabular}

\section{References}

Akis, S., Peristianis, N., \& Warner, J. (1996). Residents' attitudes to tourism development: The case of Cyprus. Tourism management, 17(7), 481-494. doi:Doi 10.1016/S0261-5177(96)00066-0

Ap, J. (1990). Residents Perceptions Research on the Social Impacts of Tourism. Annals of Tourism Research, 17(4), 610-616. doi:Doi 10.1016/0160-7383(90)90032-M

Bao, J., Chen, G., \& Ma, L. (2014). Tourism research in China: Insights from insiders. Annals of Tourism Research, 45, 167-181. doi:https://doi.org/10.1016/j.annals.2013.11.006

Bao, Y. (2003). Modernity and production of space. Shanghai: Shanghai Education Press.

Benckendorff, P., \& Zehrer, A. (2013). A NETWORK ANALYSIS OF TOURISM RESEARCH. Annals of Tourism Research, 43, 121-149. doi:https://doi.org/10.1016/j.annals.2013.04.005

Biddulph, R. (2015). Limits to mass tourism's effects in rural peripheries. Annals of Tourism Research, 50, 98-112. doi:https://doi.org/10.1016/j.annals.2014.11.011

Boano, C. (2015). Henri Lefebvre, Toward an Architecture of Enjoyment. The Journal of Architecture, 20(3), 544-549. doi:10.1080/13602365.2015.1050900

Bourdieu, P., \& Passeron, J.-C. (1990). Reproduction in education, society and culture (Vol. 4 \%@ 0803983204): Sage.

Buzinde, C. N., \& Manuel-Navarrete, D. (2013). THE SOCIAL PRODUCTION OF SPACE IN TOURISM ENCLAVES: MAYAN CHILDREN'S PERCEPTIONS OF TOURISM BOUNDARIES. Annals of Tourism Research, 43, 482-505. doi:https://doi.org/10.1016/i.annals.2013.06.003

Cárdenas-García, P. J., Sánchez-Rivero, M., \& Pulido-Fernández, J. I. (2015). Does tourism growth influence economic development? Journal of Travel Research, 54(2), 206-221.

Cheer, J. M., Reeves, K. J., \& Laing, J. H. (2013). TOURISM AND TRADITIONAL CULTURE: LAND DIVING IN VANUATU. Annals of Tourism Research, 43, 435-455.

doi:https://doi.org/10.1016/j.annals.2013.06.005 
Chen, C.-M., Lin, L., \& Chiu, H.-H. (2016). Advertising medium effect on tourist satisfaction. Annals of Tourism Research, 57, 268-272. doi:https://doi.org/10.1016/j.annals.2015.11.016

Cole, F. L. (1988). Content analysis: process and application. Clinical Nurse Specialist, 2(1), 53-57.

Cornet, C. (2015). Tourism development and resistance in China. Annals of Tourism Research, 52, 29-43. doi:https://doi.org/10.1016/i.annals.2015.02.002

Deery, M., Jago, L., \& Fredline, L. (2012). Rethinking social impacts of tourism research: A new research agenda. Tourism management, 33(1), 64-73. doi:10.1016/j.tourman.2011.01.026

Denzin, N. K., \& Lincoln, Y. S. (1994). Handbook of qualitative research: Sage publications, inc.

Doxey, G. V. (1975). A Causation Theory of Visitor-Resident Irritants: Methodology and Research Inferences. Paper presented at the The Impact of Tourism, Sixth Annual Conference Proceedings of The Travel Research Association Salt Lake City.

Duara, P. (1996). Rescuing history from the nation: Questioning narratives of modern China: University of Chicago Press.

Elden, S. (2004). Between Marx and Heidegger: Politics, philosophy and Lefebvre's The Production of Space. Antipode, 36(1), 86-105. doi:DOI 10.1111/j.1467-8330.2004.00383.x

Elden, S. (2007). There is a Politics of Space Because Space is Political: Henri Lefebvre and the Production of Space. Radical Philosophy Review, 10(2), 101-116.

Elo, S., \& Kyngäs, H. (2008). The qualitative content analysis process. Journal of advanced nursing, 62(1), 107-115.

Esman, M. R. (1984). Tourism as Ethnic Preservation - the Cajuns of Louisiana. Annals of Tourism Research, 11(3), 451-467. doi:Doi 10.1016/0160-7383(84)90031-8

Flick, U. (2004). Triangulation in qualitative research. A companion to qualitative research, 3, 178-183.

Foucault, M. (1986). Of other spaces Diacritics. Spring, 22-27.

Getz, D. (1992). Tourism Planning and Destination Life-Cycle. Annals of Tourism Research, 19(4), 752770. doi:Doi 10.1016/0160-7383(92)90065-W

Gottdiener, M. (1993). A Marx for Our Time Henri Lefebvre and the Production of Space. Sociological Theory, 11(1), 129-134.

Greenwood, D. J. (1989). Culture by the pound: An anthropological perspective on tourism as cultural commoditization. In V. J. Smith (Ed.), Host and guests: The anthropology of tourism (pp. 171185). Philadelphia: University of Pennsylvania Press.

Haller, A. O. (1974). Social Stratification and Career Mobility - Muller,W and Mayer,Ku. Rural Sociology, 39(4), 553-555.

Hampton, M. P. (2005). Heritage, local communities and economic development. Annals of Tourism Research, 32(3), 735-759. doi:https://doi.org/10.1016/j.annals.2004.10.010

Harper, M., \& Cole, P. (2012). Member checking: can benefits be gained similar to group therapy? The qualitative report, 17(2), 510-517.

Harvey, D. (1989). The Urban Experience. Oxford: Blackwell.

Hennink, M., Hutter, I., \& Bailey, A. (2010). Qualitative research methods: Sage. 
Horn, C., \& Simmons, D. (2002). Community adaptation to tourism: comparisons between Rotorua and Kaikoura, New Zealand. Tourism management, 23(2), 133-143. doi:Doi 10.1016/S02615177(01)00049-8

Inchausti-Sintes, F. (2015). Tourism: Economic growth, employment and Dutch Disease. Annals of Tourism Research, 54, 172-189. doi:https://doi.org/10.1016/j.annals.2015.07.007

Ishii, K. (2012). The impact of ethnic tourism on hill tribes in Thailand. Annals of Tourism Research, 39(1), 290-310. doi:https://doi.org/10.1016/i.annals.2011.05.004

Jafari, J. (1989). Tourism and change in lifestyle. Annals of Tourism Research, 272-273

Kordel, S. (2014). The production of spaces of the 'good life' - the case of lifestyle migrants in Spain. Leisure Studies, 35(2), 129-140. doi:10.1080/02614367.2014.962592

Lam, T., \& Hsu, C. H. (2004). Theory of planned behavior: Potential travelers from China. Journal of Hospitality \& Tourism Research, 28(4), 463-482.

Lefebvre, H. (1991). The production of space (D. Nicholson-Smith, Trans.). USA, UK, Australia: Blackwell Publishing.

Leiper, N. (1990). Tourist attraction systems. Annals of Tourism Research, 17, 367-384.

Light, D. (2007). Dracula tourism in Romania Cultural identity and the state. Annals of Tourism Research, 34(3), 746-765. doi:https://doi.org/10.1016/i.annals.2007.03.004

Lin, C. (2015). Red Tourism: Rethinking Propaganda as a Social Space. Communication and Critical/Cultural Studies, 12(3), 328-346. doi:10.1080/14791420.2015.1037777

Ma, J. (1998). Economic change in Hui community, Sanya, Hainan. Journal of Guangxi University for nationalities (Philosophy and Social Science Edition), 20(3), 52-55.

Marx, K. (2011). Capital, volume one: A critique of political economy. Trans. Samuel Moore and Edward Aveling. Ed. Freidrich Engels. Mineola, NY: Dover Publications.

Mazanec, J. A. (2009). Unravelling myths in tourism research. Tourism Recreation Research, 34(3), 319323.

McKercher, B., \& Prideaux, B. (2014). Academic myths of tourism. Annals of Tourism Research, 46, 1628. doi:10.1016/j.annals.2014.02.003

McKercher, B., Wang, D., \& Park, E. (2015). Social impacts as a function of place change. Annals of Tourism Research, 50, 52-66. doi:https://doi.org/10.1016/j.annals.2014.11.002

Medina, L. K. (2003). COMMODITIZING CULTURE Tourism and Maya Identity. Annals of Tourism Research, 30(2), 350-368. doi:doi:10.1016/S0160-7383(02)00099-3

Merriam-Webster. (2019). Retrieved from https://www.merriam-webster.com/dictionary/culture

Mueller, G. E. (1958). The Hegel Legend of" Thesis-Antithesis-Synthesis". Journal of the History of Ideas, 19(3), 411-414.

Nash, D. (1996). Anthropology of Tourism: Emerald Group Publishing Limited.

Nicholls, S. (2004). Climate Change and Tourism. Annals of Tourism Research, 31(1), 238-240. doi:https://doi.org/10.1016/j.annals.2003.08.006

Nunkoo, R., Smith, S. L. J., \& Ramkissoon, H. (2013). Residents' attitudes to tourism: a longitudinal study of 140 articles from 1984 to 2010. Journal of Sustainable Tourism, 21(1), 5-25.

doi:10.1080/09669582.2012.673621 
Pitchford, S. R. (1995). Ethnic Tourism and Nationalism in Wales. Annals of Tourism Research, 22(1), 3552. doi:Doi 10.1016/0160-7383(94)00068-4

Pratt, S. (2011). Economic linkages and impacts across the talc. Annals of Tourism Research, 38(2), 630650. doi:https://doi.org/10.1016/j.annals.2010.11.014

Purcell, M. (2013). Ruling Los Angeles: Neighborhood Movements, Urban Regimes, and the Production of Space in Southern California. Urban Geography, 18(8), 684-704. doi:10.2747/02723638.18.8.684

Redman, M. B. (1983). Economic Impact of a short-term tourism industry exposition a coment. Annals of Tourlsm Research, 10, 435-436.

Ruhanen, L., Moyle, C.-I., \& Moyle, B. (2018). New directions in sustainable tourism research. Tourism Review.

Smith, A., \& David, N. (1995). The Production of Space and the House of Xidi Sukur. Current Anthropology, 36(3), 441-471. doi:Doi 10.1086/204379

Smith, V. L. (1989). Host and Guests: The Anthropology of Tourism (Second ed.). Philadelphia: University of Pennsylvania Press.

Soja, E. W. (1996). Thirdspace: Journeys to Los Angeles and Other Real-and-Imagined Places: WileyBlackwell.

Stanek, L. (2008). SPACE AS CONCRETE ABSTRACTION. Space, Difference, Everyday Life: Henri Lefebvre and Radical Politics. (pp. 62-79): Routledge.

Steel, G. (2012). Local encounters with globetrotters. Annals of Tourism Research, 39(2), 601-619. doi:10.1016/j.annals.2011.08.002

Stemler, S. (2001). An overview of content analysis. Practical assessment, research \& evaluation, 7(17), 137-146.

Teye, V. B. (1993). Socio-Environmental Changes in Leisure and Tourism. Annals of Tourism Research, 20(2), 374-375. doi:Doi 10.1016/0160-7383(93)90067-D

Vaismoradi, M., Turunen, H., \& Bondas, T. (2013). Content analysis and thematic analysis: Implications for conducting a qualitative descriptive study. Nursing \& health sciences, 15(3), 398-405.

Wall, G., \& Ali, I. M. (1977). The impact of tourism in Trinidad and Tobago Annals of Tourism Research, 4, 43-49.

Wang, S., \& Chen, J. S. (2015). The influence of place identity on perceived tourism impacts. Annals of Tourism Research, 52, 16-28. doi:https://doi.org/10.1016/i.annals.2015.02.016

Woo, E., Uysal, M., \& Sirgy, M. J. (2018). Tourism impact and stakeholders' quality of life. Journal of Hospitality \& Tourism Research, 42(2), 260-286.

Xuan, Z. (2011). Hut nationality in Hainan. Beijing: Chinese cultural press.

Yang, J., Ryan, C., \& Zhang, L. (2016). Impersonation in ethnic tourism - The presentation of culture by other ethnic groups. Annals of Tourism Research, 56, 16-31. doi:https://doi.org/10.1016/j.annals.2015.10.005

Yang, L., Wall, G., \& Smith, S. L. J. (2008). Ethnic tourism development. Annals of Tourism Research, 35(3), 751-771. doi:10.1016/j.annals.2008.06.005

Yeung, H. W. C. (1998). Capital, state and space: contesting the borderless world. Transactions of the Institute of British Geographers, 23(3), 291-309. doi:DOI 10.1111/j.0020-2754.1998.00291.x 